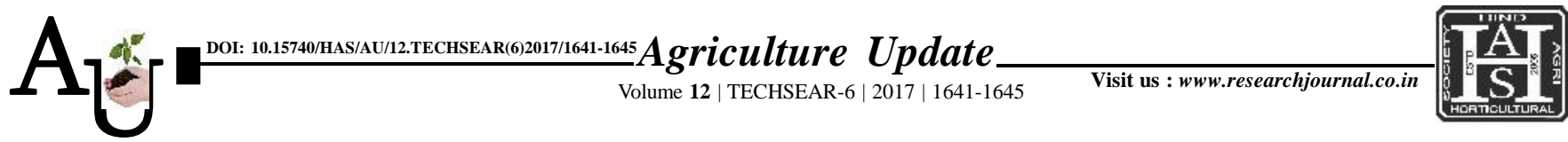

\title{
Reserct Article: Influence of biochar, phosphorus and mycorrhiza on nutrient content of baby corn (Zea mays L.)
}

\section{ARGHYA CHATTAPADHYAY, A.P. SINGH, AWTAR SINGH AND AJOY DAS}

Article Chronicle : Received : 17.07.2017;

Accepted : 01.08 .2017

Key Words:

Biochar, Mycorrhiza, Phosphorus
SUMMARY : A pot experiment was conducted in the Department of Soil Science and Agricultural Chemistry, Institute of Agricultural Sciences B.H.U., Varanasi, India during Kharif season of 2015 to investigate the influence of biochar, phosphorus and mycorrhiza on performance of baby corn and soil quality. The treatments comprised of four levels of biochar i.e. No biochar, rice husk biochar, lantana biochar and parthenium biochar (each applied @ $4.545 \mathrm{~g} \mathrm{~kg}^{-1}$ soil, two levels of mycorrhiza (uninoculated and inoculated) and two levels of phosphorus viz., no P and P @ 50\% RDF along with full dose of nitrogen and potassium were applied. One of the important findings of the investigation showing beneficial effects of biochar could be exploited if it was applied along with mycorrhiza. Combined application of biochar (10 tha ${ }^{-1}$ soil) along with mycorrhiza was produced significantly higher nutrients concentration in baby corn.

How to cite this article : Chattapadhyay, Arghya, Singh, A.P., Singh, Awtar and Das, Ajoy (2017). Influence of biochar, phosphorus and mycorrhiza on nutrient content of baby corn (Zea mays L.). Agric. Update, 12(TECHSEAR-6) : 1641-1645; DOI: 10.15740/HAS/AU/12. TECHSEAR(6)2017/1641-1645.
Author for correspondence :

\section{ARGHYA}

\section{CHATTAPADHYAY}

Department of Soil

Science and Agricultural Chemistry, Banaras

Hindu University,

VARANASI (U.P.) INDIA

Email:arghyachattbckv

@ gmail.com 